\title{
Wireless "Questions-Bank" System to enhance M-learning in School Education
}

\author{
doi:10.3991/ijim.v4i1.1129 \\ Samir A. El-Seoud ${ }^{1}$, Hosam F. El-Sofany ${ }^{2}$, and Yahia Al-Halabi ${ }^{1}$ \\ ${ }^{1}$ Princess Sumaya University for Technology, Amman, Jordan \\ ${ }^{2}$ Qatar University, Doha, Qatar
}

Diese Arbeit ist Herrn Professor Dr. Willi Törnig zu seinem 80. Geburtstag gewidmet

\begin{abstract}
Through wireless devices and wireless applications, M-learning supports an integrated access to Web content and services in education anytime and anywhere. This paper describes the analysis, design, and implementation of "Wireless Questions-Bank System", that allows the students to take web-based quizzes, web-based free exercises, webbased exams (midterm, and final), to download course reviews, to download previous exams and their model answers, to access the system through the Mobile and take quick quizzes and exercises. The system facilitates generation of automatic, balanced, and different exam sheets, that containing different types of questions, covering the entire curriculum, and displaying gradually from easiness to difficulty. The exam sheet produced by the system, takes into account the different levels of the students from excellent, good, to fair, and avoids any mistakes of language and nonclear terminologies.
\end{abstract}

Index Terms - e-learning, m-learning, mobile technology, educational systems

\section{INTRODUCTION}

Introducing Internet at schools has encouraged the development of new tools and systems within the scope of education and training. As a result, a new area of learning and training approaches has emerged, where new educational models have been developed, students could learn independently at any time or location, simply by connecting to the Net along with the appropriate systems and tools. Teachers, at the same time, could teach through "on-line" setting and could schedule lessons and exams without the classical physical constraints. This electronic learning approach, also known as e-learning, has opened new horizons in teaching for both teachers and students [1-4].

The assessment process in an educational system is an important and primordial part of its success to assure the correct way of knowledge transmission and to ensure that students are working correctly and succeed to acquire the needed knowledge. Many assessment methods can be used: conducting some experiments, realizing different mini-projects, making quizzes and exams. The evaluation mechanism help students to discover whether they have gained the required knowledge as expected, and provide appropriate and timely feedback to teachers to adjust their lectures, exercises and exams [5-7].

The demand for mobile Internet access is driving the development of a new generation of wireless devices and wireless applications. The greatest demand for WAP
(Wireless Application Protocol) applications has been within the business world. As a result, real-time applications that can access corporate LANs, intranets, databases, email, and messaging applications are the first types of applications one might encounter as a wireless Internet user. The demand for WAP applications goes far beyond the corporate world. Real-time delivery of wireless content is a type of application that all users will find beneficial. Wireless users require and expect access to the Internet content and Web services similar to that of today's Internet users [8,9].

The paper is organized as follows: in section two we give a brief overview about the Questions-Bank system while in section three we present the system analysis and design. In section four we describe the system implementation. In section five we introduce the mobile technology, and describe the Mobil-based development of the system. In section six we evaluate the system. The paper is finally concluded in section seven.

\section{SYSTEM OVERVIEW}

The system interface is entirely web-based, and doesn't necessitate any technical skills from the potential users. The system is divided into three applications, called administrator, teacher, and student application. As shown in Figure 1, the system is appropriate for on-campus teaching, with access to the Internet, or off-campus teaching using the local network.

The proposed Questions-Bank System has the following functionalities and features:

Knowledge evaluation: Students can evaluate their understanding levels, and teachers can track the activities of their students and can guide them to reach the predetermined objectives of the courses.

Exam grading: quizzes and exams can be marked automatically by the system. Thus, students can get instantly their marks in a given quiz immediately after submitting their responses and see also the corrected answers.

Communication: The system has a communication tool that allows students and teachers to interact together and discuss their activities.

Course management: The system is highly flexible and doesn't necessitate any programming skills from its potential users. Thus, teachers can add, delete and update their course materials at any moment through the web.

Questions-Bank database: The system allows the schools to create a Questions-Bank database that stores the previous exams, the model answers, the reviews, and useful exercises for each course. 


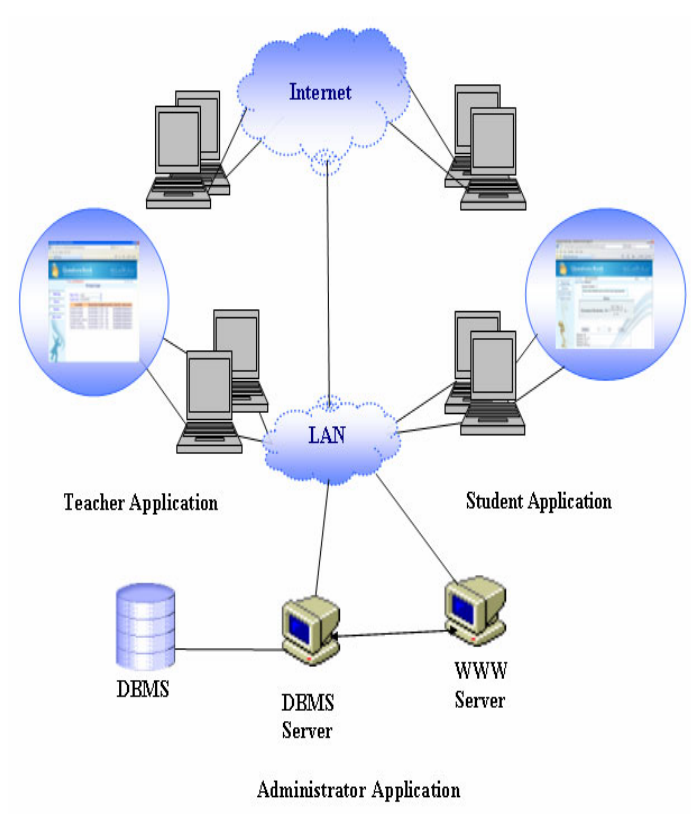

Figure 1. System overview

\section{System ANALYSIS AND DESIGN}

Adopted Software Development Process: Software development process represents the structure imposed on the development of a software product, which includes software life cycle and software process. The process involves translating user needs into software requirements, transforming the software requirements into design, implementing the design in code, testing the code, and sometimes installing and checking out the software for operational activities [10].

Life Cycle Model: Many models have been proposed to handle the problems of defining activities and associating them together. Our adopted software development process is the V-model, as shown in Figure 2, which can be presumed to be the extension of the Waterfall model [11]. Instead of moving down in a linear way, the process steps are bent upwards after the implementation phase, to form the typical V shape. In the development of the Questions-Bank system, the V-model was followed as:

1. Specifying the system requirements using different gathering approaches.

2. The requirements were analyzed and classified into functional and nonfunctional requirements, and use cases and domain model were constructed.

3. The system design was started by determining the database tables, appropriate interfaces, class diagram: to show a static view of used classes, and interaction diagrams: to show the collaborations among the objects of the system to complete an action.

4. The implementation phase was launched by implementing the functionalities of the system.

Each of the previously mentioned phases is associated to a certain phase of testing to verify and to validate that the work is accurately executed, if problems are found during the verification or validation phases, then a reexecution of left side of the $\mathrm{V}$ is performed to make fixes and improvements.

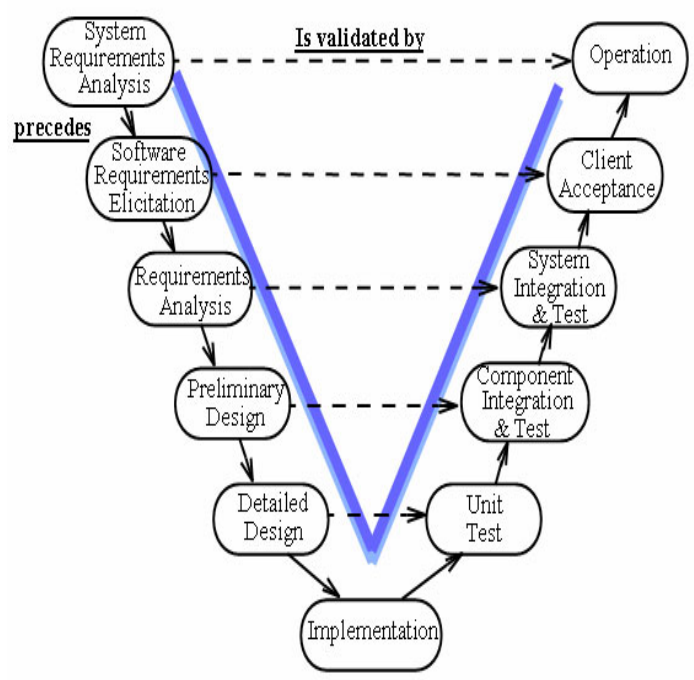

Figure 2. The V-model - Software development process

\section{A. System Analysis}

The analysis phase is the chief phase in which the system requirements are identified in more details. The goal of this phase in the system development is to refine the system goals into defined functions and operation of the intended application. System requirements are documented in a complementary set of artifacts: flow charts use case diagrams, system sequence diagrams and so on. Each artifact provides a different perspective of the system under design and contains distinct requirements.

\section{1) System Specification}

- Functional requirements: Describe the interactions between the system and its environment independent of its implementation. The environment includes the end user and any other external system with which the system interacts.

The Questions-Bank system should allow different types of users to interact with the system according to given privileges. There are three main users: school administrator, teacher, and student. It provides various services for each one:

a Questions-Bank system allows the school administrator to:

- Login (as administrator).

- Chang account password

- Get new password instead of the lost one.

- Activate/Inactivate the system.

- Renew data (Import the data from the Excel file to the SQL server database, delete data from specific table)

- Send an email immediately containing the new password whenever the user changes his/her password.

- Manage (add, update, delete and display) the basic information of the system: levels data, subjects (or courses) data, class's data, teacher's data, and students' data.

b Questions-Bank system allows the teacher to:

- Login (as teacher).

- Change account password 
- Manage (add, update, delete and display) all the system services: reviews, exam questions, quizzes, and previous exams (with their model answers)

c Questions-Bank system allows the student to:

- Login (as student).

- Change account password

- Get new password instead of the lost one.

- Download assignments, revision documents, previous exams, and other files that are uploaded by the teachers.

- Take web-based quizzes, exams, free exercises, and interactive tutorials.

- Non-functional requirements: Describe aspects of the system that are not directly related to the functional behavior of the system.

a Usability: The system must provide a coherent user interface that is consistent with the organization interface. The system must be obvious, allowing the user to navigate the system easily.

b Reliability: The system must perform and maintain its functions in routine circumstances.

c Supportability: The system must be easily modified or extended by more functions.

d Performance: Performance requirements are concerned with quantifiable attributes of the system, such as response time, throughput availability and accuracy.

e Security: The system must prevent unauthorized users to access the system. Authorized users must be provided with user ids and passwords. In order to achieve high level of security, the password must be encrypted.

\section{B. System Design}

The design goal of our system is to resolve some of the issues, specifically; it is to be made easily accessible and customizable. The system will be designed as a web application requiring only a web browser administer and use.

\section{1) Design Methodology and Patterns}

A methodology is a collection of methods for solving a class of problems. It specifies which method should be used and the manner in which it is utilized. Software development methodologies decompose the process into activities. They provide methods for several activities as shown in Figure 3.

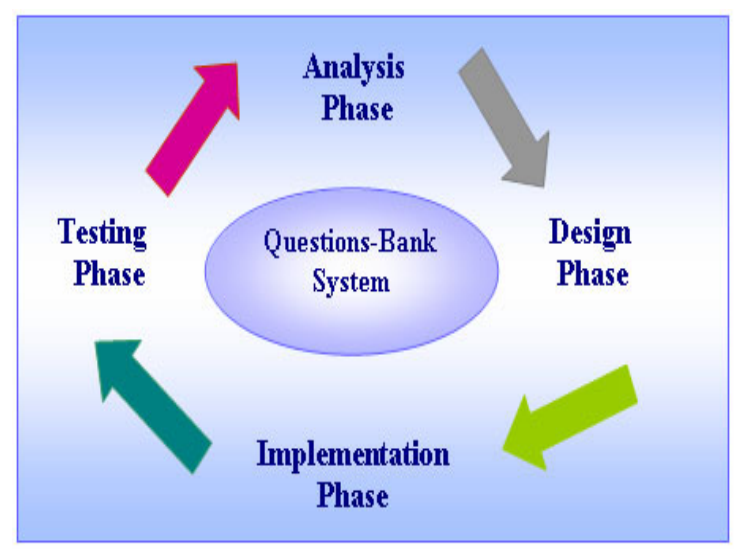

Figure 3. Software development methodologies

\section{2) Database Design}

Database is an important component in our system. Microsoft SQL Server database is the database management system used for the system. The implementation of the database has been developed and modified many times to be applicable with the system requirement. The DBMS stores the subjects in each school level, the reviews, the previous examinations, the exams questions, the quizzes, the student grades, and the basic information of the administrator, teacher, and student. We have chosen the entity-relationship model to represent the database design [12].

\section{3) System Architecture}

The "Questions-Bank" system consists of three components as shown in Figure 1: The client, the server, and the database management system (DBMS). The client side application is developed by web-based programming languages such as XHTML, ASP.NET, Macromedia Flash and Java script. The server application is developed by Microsoft Visual Studio.NET, and acted as a gateway between the database and the clients. The system information are stored and managed using Microsoft SQL Server database. The database and the server applications will run on Microsoft Windows Server.

\section{WEB-BASED SYSTEM DEVELOPMENT}

The web-based "Questions-Bank" system takes the advantage of the latest development technologies in its implementation. It is an ASP.NET web application to be used on the Internet and was written using Microsoft's Visual Studio .NET development environment in the C\# programming language. Microsoft's SQL Server 2008 is used for database operations, including the storage and retrieval of login information.

To prove the functionality of the "Questions-Bank" system, we have implemented several web-based applications as components of the system. The Questions-Bank system is divided into three sub-systems: the administrator, the teacher, and the student sub-system.

\section{Introducing Mobile TeChNOLOGY}

\section{A. The Wi-Fi Network Technology}

A wireless network uses radio waves that communicate in two ways: a centralized network with access point, called infrastructure network and, a decentralized network without access point, called ad-hoc network. In an educational context as of the wireless network implementations to date, WiFi) Wireless Fidelity) technology is widely used in comparison to others wireless networks. So, in this paper, we'll focus on infrastructure WiFi network. A computer's wireless adapter converts the message or data to be sent into radio signals and transmits them using an antenna. The wireless access point that is already connected to an existing local area network (or directly to Internet) receives the incoming radio signal and decodes it. It forwards that information to the Internet or to any computer on the local network. The process also works backwards, with the access point or router receiving information from the Internet or destination computer, converting it into radio signals and sending it back to the source computer. The radio transmission happens at frequencies of $2.4 \mathrm{GHz}$ or $5 \mathrm{GHz}$, which is considerably higher than the frequencies used for cell phones, televi- 
sions etc. The higher frequency allows the signal to carry more data [13].

\section{B. System Architecture Scenario}

- To start building the proposed Web-based Mlearning applications, we will need a Windows Server running Internet Information Services (IIS) and the .Net Framework.

- The MS Mobile Internet Toolkit extends the functionality of the ASP.NET to easily target mobile devices using mobile Web Forms technology. We can use .NET framework services like XML Web Services, ADO.NET for data Access and the Common Language Runtime.

- Once the Web server and the mobile Web application are deployed on the Internet. The wireless device that wants to access the mobile Web application will make an HTTP request to the Web server.

- The HTTP request will be processed on the server in three main stages (Device capabilities, Mobile .aspx pages, and Mobile controls \& device adapters generate display). The first process is identifying the requesting device in this instance "a wireless device" and the capabilities of that device, for example: browser, mark-up language, and image capabilities.

- The MS Mobile Internet Toolkit extends the .NET Framework Machine.config schema with mobile device capabilities and pre-populates the device data. The Machine.config file applies to all applications on the server and the web.config file applies to specific application.

- The HTTP request from the wireless device contains the User Agent string, Header information and URL that is being requested. The User Agent string is matched against entries in the Machine.config file.

- The URL from the HTTP request is then used to locate the corresponding mobile Web page which will have a .aspx file extension.

- The first time that a ASPX page is accessed, the page will be compiled. The ASPX page will be send to the parser; once the page has been parsed it will be processed by the compiler. The compiled page is then stored in the Assemble Cache. The server then creates a new instance of the compiled page, and uses it to process the request.

- Once the page has been compiled, the parsing and compiling steps do not need to be repeated for each request, the compiled page class can be reused, resulting in improved performance.

- The device adapters associated with the requesting device and controls used on the page then generate the appropriate mark-up language, in this case HTML for wireless devices.

- The HTML is then encapsulated in an HTTP response and returned to the requesting wireless device.

- When a WML browser accesses the same mobile web application as the wireless device, it goes through the following steps. The WAP browser makes a WAP request to a WAP Gateway. Usually, these gateways are a service provided by wireless carriers. The WAP Gateway translates the WAP re- quest to an HTTP request and passes it to the web server over the internet $[14,15]$.

\section{Mobil-based System Development}

To improve the functionality of the "Questions-Bank" system, we are implementing several wireless applications as components of the M-learning system [16].

- The Student Applications: A student accesses the Mlearning system through the URL. The system should ask the student to login in first, as shown in Figure 4(a). Once the student has a valid login name (student ID) and a password, he/she can login to the system applications and choose a course from the list of courses in which the student enrolled.

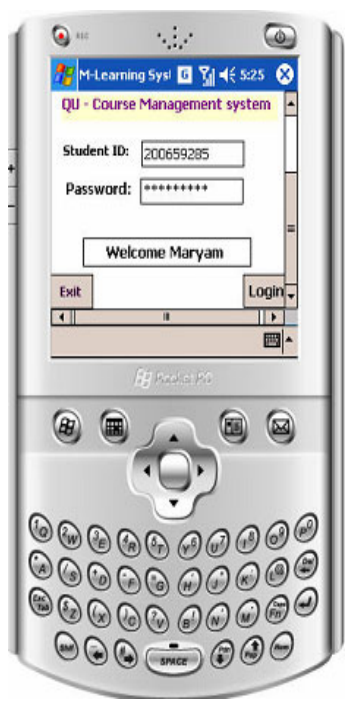

a) Login and authentication

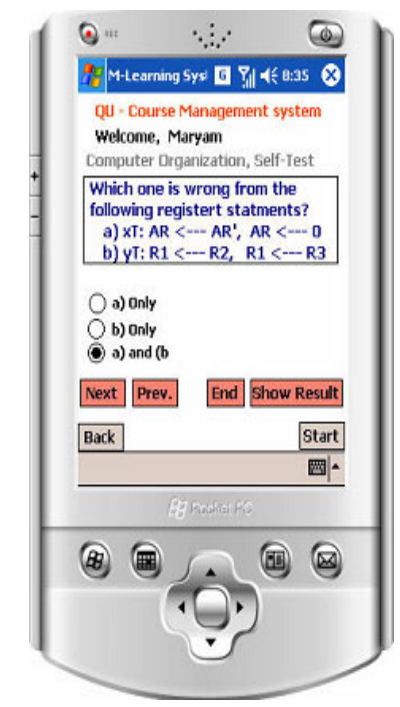

b) Wireless quizzes
Figure 4. The Student Application

- Wireless Tests/Quizzes: The wireless student tests/quizzes application allows a test to be taken not just anytime, but anywhere through a wireless mobile device. The tests are generated dynamically on the Web server by ASP.NET code and are delivered by WML code and with timing constraints on the WAP device's micro-browser. The selected answers are transferred from the micro-browser back to the Web server (ASP.NET code) where they are checked against the correct answers (with weights) in the tests database table. The test score is calculated and displayed in the micro-browser using a separate WML card, as show in Figure 11(b).

\section{SYSTEM EVALUATION}

To obtain some feedback about the "Questions-Bank" system, we have prepared a questionnaire and distribute it to the potential students registered in the system. Sixty students have been randomly selected to use as a testing pool. A group of 30 students have used the hard paper quiz (and review) and another similar group has used our web-based system. Table 1 shows that both groups obtained approximately similar results. Students had to obtain a grade of $60 \%$ to pass the quiz. After taking the quiz, all the students had to fill in a questionnaire with general and specific questions related to the method of testing. The most significant questions reflecting student opinion are set out in Table 2, with the relevant group responses. 
TABLE I.

QUIZ RESULTS OF THE TWO GROUPS OF STUDENTS

\begin{tabular}{|c|c|c|}
\hline Student Groups & Passed & Percentage \\
\hline A - paper quiz & 22 & $\% 73.33$ \\
\hline B - Computer quiz & 25 & $\% 83.33$ \\
\hline
\end{tabular}

TABLE II.

RESULTS OF THE UESTIONNAIRES OF BOTH GROUPS

\begin{tabular}{|l|c|c|}
\hline & Group A (\%) & Group B (\%) \\
\hline 1. Do you trust the on-line evaluation system? \\
\hline Yes & 65 & 90 \\
\hline No & 35 & 10 \\
\hline 2. When do you prefer to be told your quiz score? \\
\hline At the end & 80 & 95 \\
\hline Later & 20 & 5 \\
\hline $\begin{array}{l}\text { 3. How would you describe the process of entering answers in } \\
\text { the computer? }\end{array}$ & - & 75 \\
\hline Easy & - & 22 \\
\hline Acceptable & - & 3 \\
\hline Difficult & - & - \\
\hline Very difficult & $\begin{array}{l}|c| \\
\text { How do you feel your result would have been, if the quiz had } \\
\text { been on paper as the traditional way? }\end{array}$ \\
\hline Worse & - & 25 \\
\hline Same & - & 40 \\
\hline Better & - & 5 \\
\hline Do not know & - & - \\
\hline 5. How do you feel your result would have been, if the quiz \\
\multicolumn{2}{|c|}{ had been by the on-line system (i.e., computer-based)? } \\
\hline Worse & 40 & - \\
\hline Same & 30 & - \\
\hline Better & 20 & - \\
\hline Do not know & 10 & \\
\hline
\end{tabular}

\section{CONCLUSION}

This paper describes the experimental development of the Questions-Bank System, that allows the school students to take web-based quizzes, to take web-based free exercises, to take web-based exams (monthly, midterm, and final), to download course reviews, to download previous exams and their model answers, to access the system through the Mobile and take quick quizzes and exercises. The system facilitates generation of automatic, balanced, and different exam sheets, that containing different types of questions, covering the entire curriculum, and displaying gradually from easiness to difficulty. The exam sheet produced by the system, takes into account the different levels of the students from excellent, good, to fair, and avoids any mistakes of language and non-clear terminologies.

\section{REFERENCES}

[1] Hosam F. El-Sofany, Samir A. El-Seoud, Shaima Ibrahim, and Noor Al-Jaidah, "Questions-Bank System to Enhance E-Learning in School Education". Proc. 4th International Conference on "Interactive Mobile and Computer aided Learning -IMCL07". PSUT, April 22-24, Amman, Jordan 2009.
[2] Hosam F. El-Sofany, Samir A. El-Seoud, Fayed F. M. Ghaleb, Sameh S. Daoud, Jihad M. AL Jaam, and Ahmad M. Hasna, "XML and Databases for E-Learning Applications. International Journal of Emerging Technologies in Learning - iJET. Vol. 2, No. 4, Pages 6-12, 2007.

[3] Hosam F. El-Sofany, Ahmad Hasna, Jihad Jaam, Fayed Ghaleb, and Samir A. El-Seoud, "A Web-Based E-Learning System Experiment". International Journal of Computing \& Information Sciences (IJCIS), Vol. 4, No. 1, P22-29, April 2006.

[4] M.S. Abdel Wahab and et al. "Case Study: Design and Development of an Online Course". Proc. 9th International Conference on Interactive Computer Aided Learning - ICL 2006. September $27-$ 29, Villach, Austria, 2006.

[5] Badariah S. and Rosnafisah S. "Rapid E-Learning Content Management System (RE-COMS)". International Journal of Computing \& Information Sciences (IJCIS), Vol. 4, No. 1, P1-9, April 2006.

[6] R. Lister \& P. Jerram. Design for web-based on-demand multiple choice exams using XML, Proc. of the IEEE International Conf. on Advanced Learning Technologies 2001, Madison, WI, USA, 2001, 383-384.

[7] G. C. Fox, Initial discussion of use of XML for universal access, shared places on the web: XML for web-based collaboration and distance education. XML Developers Conf., Montreal, Canada, 1999.

[8] Seibu Mary Jacob and Biju Issac. Mobile Technologies and its Impact - An Analysis in Higher Education Context. iJIM - Volume 2, Issue 1, January 2008

[9] Seibu Mary Jacob and Biju Issac, "Mobile Technologies and its Impact - An Analysis in Higher Education Context". International Journal of Interactive Mobile Technologies (iJIM) - Volume 2, Issue 1, January 2008.

[10] Bernd Bruegge and Allen H. Dutoit, Object-Oriented Software Engineering using UML, Patterns, and Java, United States,2004.

[11] http://en.wikipedia.org/wiki/Waterfall_model

[12] Ramez Elmasri and Shamkant B. Navathe. Fundamentals of Database System. Addison-Wesley, fifth edition, 2007.

[13] K. E. Smith and O. Cap, "Impact on Social Change: Benefits and Barriers to School Culture and the Integration of M-Technology". International Journal of Interactive Mobile Technologies (iJIM) Volume 2, Issue 1, January 2008.

[14] http://www.asp.net/mobile/overview/

[15] http://www.asp.net/mobile/architecture/

[16] Hosam F. El-Sofany, and Samir A. El-Seoud, "Towards the Development of an M-Learning System: A New Stage to Enhance Higher Education", Proc. 11th International Conference on Interactive Computer Aided Learning - ICL 2008. September 24- 26, Villach, Austria, 2008.

\section{AUTHORS}

Samir, Abou El-Seoud, Professor. Computer Science Department, Princess Sumaya University for Technology, Amman-Jordan. (selseoud@psut.edu.jo)

Hosam, F. El-Sofany, Lecturer. Department of Engineering and Computer Science, College of Engineering, Qatar University, Doha - Qatar. (helsofany@qu.edu.qa)

Al-Halabi, Yahia, Professor. Computer Science Department, Princess Sumaya University for Technology, Amman - Jordan. (yahiah@psut.edu.jo)

Submitted October, 30, 2009. Published as resubmitted by the authors on December, 2, 2009. 